\title{
ARDUINO E EDUCAÇÃO: INSTRUMENTALIZAÇÃO E TECNOLOGIAS NO ENSINO DA MÚSICA
}

\section{ARTIGO ORIGINAL}

OLIVEIRA, Solamy do Rocio da Silva ${ }^{1}$

COELHO, José Pedro Fernandes da Silva ${ }^{2}$

OLIVEIRA, Solamy do Rocio da Silva. COELHO, José Pedro Fernandes da Silva. Arduino e Educação: instrumentalização e tecnologias no ensino da música. Revista Científica Multidisciplinar Núcleo do Conhecimento. Ano 05, Ed. 09, Vol. 06, pp. 05-15. Setembro de 2020. ISSN: 2448-0959, Link de acesso: https://www.nucleodoconhecimento.com.br/educacao/arduino-e-educacao

\section{RESUMO}

O presente artigo busca experimentar o uso de tecnologias digitais para o letramento musical em instrumentos de sopro, precisamente o clarinete, e analisar como o uso da tecnologia pode e deve ser associada a iniciação musical, questionando de que modo podemos estimular a aprendizagem a partir de novas técnicas ou associações entre arte e tecnologia. Para tanto, buscamos apresentar um artefacto em fase de experimentação que permita melhorar o aprendizado na fase de iniciação musical, o

\footnotetext{
${ }^{1}$ Doutoranda em Média-Arte Digital, pela Universidade Aberta de Lisboa, Mestra em Artes pela Universidade Federal da Bahia (2017). Graduada nas seguintes universidades: Licenciatura em Música pela Faculdade de Artes do Paraná (1988) e na Universidade Federal da Bahia curso Bacharelado em clarinete 1992 a 1996. Especialização em História e Cultura Afro-Brasileira 2006-2007 Tem experiência na área de Artes, com ênfase música. Cidade de atuação Salvador/Bahia /Brasil.

${ }^{2}$ Orientador. Doutor em Engenharia de sistemas. Mestre em Investigação Operacional e Engenharia de Sistemas. Graduado em Engenharia Informática e de Computadores (Licenciatura).
} 
Arduíno. Tal artecfato pode ser utilizado com instrumentos de sopro, através do reconhecimento das notas da escala natural e associando as mesmas com as cores do arco-íris, assim como foi realizado no experimento. Utilizamos da Tecnologia de Informação e Comunicação, cada vez mais presente na nossa vida, como atrativo para os alunos e com os avanços tecnológicos como complementares à atividade artísticas. Assim, objetiva-se avaliar o desempenho e a aprendizagem dos alunos visto que do lúdico favorece a criação de um ambiente e método que incentivam a aprendizagem. Percebe-se o potencial da união entre instrumentos musicais antigos, como o clarinete, com as inovações trazidas com a tecnologia digital. Com este trabalho, evidenciou-se também a lacuna teórica e prática que existe acerca deste tema e a necessidade de maior produção experimental sobre o mesmo.

Palavras-chave: clarinete, iniciação musical, arduíno, tecnologia.

\section{INTRODUÇÃO}

Estamos cotidianamente envolvidos com as Tecnologias de Informação e Comunicação, em todas as áreas da vida, e particularmente no campo da arte algumas propostas metodológicas são implementadas a fim de incentivar o uso das tecnologias como um valioso complemento à atividade artística. Porém, estas aplicações ainda são generalizadas e são observadas deficiências quanto à disponibilidade de opções para a sua união com a música.

Não há muito o que afirmar sobre a criação da música, porém, é possível predizer que a conceituação sobre a música começa nos primórdios da sociedade. Dentre as formas variadas de comunicação, a música pode, também, estar entre as mais antigas, sendo ela usada para cultos religiosos, celebrações ou até mesmo para a própria comunicação. Levando em consideração o fato de não haver uma data ou algo parecido para falar da criação da música, deduzimos que o homem, em sua cabeça mais primitiva, conseguia produzir música através dos instrumentos - aqui entendidos como todos instrumentos utilizados para a vida diária. 
A música é uma arte completa, e quando se está na posição de ouvinte, ela - a música - proporciona diversas sensações que apenas a arte consegue transmitir, como euforia, nostalgia, tristeza, etc. Portugal e Corrêa (2017, p 207) dizem que "a música, por meio de manipulação numérica e da relação proporcional entre os sons, poderia afetar a alma e o caráter. [...] a expressão do belo e das sensações que a música poderia propiciar". Portanto, os instrumentistas ao experimentarem essas sensações com autenticidade cumprem com êxito o seu trabalho artístico. Com apoio da arte visual, buscamos unir a expressão auditiva e a visual.

$\mathrm{Na}$ literatura de projetos similares, principalmente voltadas à didática da música de modo geral, no que tange, por exemplo, ao aprendizado iniciado de um instrumento musical, apesar de promissora, ainda evidencia iniciativas insuficientes, principalmente com integração entre cores e notas musicais, sendo o presente estudo uma oportunidade para reflexão sobre o tema com conteúdo experimental, buscando mostrar a possibilidade de realizar a união das expressões artísticas visuais com as musicais por meio de um hardware livre, o Arduíno.

A cada nota musical, será atribuída, por meio do software, uma cor que aparecerá em um artefato que exibirá uma luz brilhante correspondente. Foram escolhidas apenas sete cores, pois uma escala musical é formada por sete notas musicais naturais, como explica Bezerra (2019).

\section{CONCEITO, DESENHO, IMPLEMENTAÇÃO E PROCESSAMENTO DO ARTEFATO ARDUINO}

A representação da música através da cor, a fim de criar uma metáfora entre tons musicais e tons de cores, bem como a representação de ritmo e harmonia busca ser utilizada no presente trabalho como ferramenta facilitadora da aprendizagem, para tanto se criou um artefacto que por meio da utilização do software se imprime uma cor a cada vez que se toca uma nota musical, fazendo com que os estudantes tenham uma experiência sinestésica capaz de ajudá-los a memorizar mais rapidamente e eficientemente as notas musicais, podendo estar ser utilizado no ensino de qualquer 
instrumento musical de sopro, ainda que para efeito do presente estudo se utilize o clarinete.

Para Bohumil (1996) embora seja inúmeros os sons empregados na música, para representá-los bastam somente sete notas: dó - ré - mi - fá - sol - lá - si.

Cada nota terá sua cor de acordo com a sequência das cores do arco-íris:

Dó - Vermelho: Simboliza paixão, amor e coragem. Também pode transmitir sentimentos de agressividade.

Ré - Laranja: Representa a comunicação, cordialidade e prosperidade.

Mi - Amarelo: Significa alegria, luz, jovialidade.

Fá -Verde: Evoca sentimentos de esperança, paz, equilíbrio e confiança.

Sol - Azul: Simboliza calma mental, harmonia e autoridade. Também pode transmitir sentimentos de frieza.

Lá - Anil: Significa sinceridade, respeito e individualidade.

Si - Violeta: Também descrita como roxo, a cor violeta está relacionada com a espiritualidade.

Escolhemos as cores do arco íris para simplificar a compreensão da sequência das 7 notas musicais, tornando um aprendizado dinâmico e lúdico para uma intervenção de iniciação musical. As luzes na presente pesquisa estão verificando como a cor pode ajudar na aprendizagem/memorização das notas, da escrita (notação musical) e da identificação do som. E, abrir a possibilidade da utilização dos demais sentidos, não somente a audição, na aprendizagem de música tornando-se assim um suporte para que no futuro os alunos possam perceber determinada nota sem a presença do artefacto. 


\section{DESENHO}

Quando se fala em termos de música, tem que ter em mente que uma nota musical é o símbolo que representa o som de um tom. Por convenção, existem sete tonalidades: DO, RE, MI, FA, SOL, LA e SI. Dependendo da localização das notas na pauta, qualquer um dos tons é identificado (figura).

Figura 1 - Exemplo de escala musical com cores



Segundo Priolli (2013), em relação ao estudo dos princípios básicos da música para a iniciação musical se faz necessário o conhecimento seguinte;

\subsection{TONS E SEMITONS NATURAIS: A ESCALA DIATÔNICA DE DÓ, SUA FORMAÇÃO E SEUS GRAUS}

O Semitom é menor intervalo, entre dois sons, que o ouvido pode perceber e classificar. Tom é definido como o intervalo, entre dois sons, formado por dois semitons. E a Escala diatônica é a sucessão de 8 sons conjuntos guardando de um para outro intervalo de tom ou de semitom. 
Figura 2 - Escala ascendente e Escala descendente



Fonte: Priolli, 2013, p.29

Os tons e semitons contidos na escala diatônica são chamados naturais. A cada uma das notas da escala, de acordo com a sua função na própria escala, dá-se o nome de grau.

Figura 3 - Graus das notas na escala

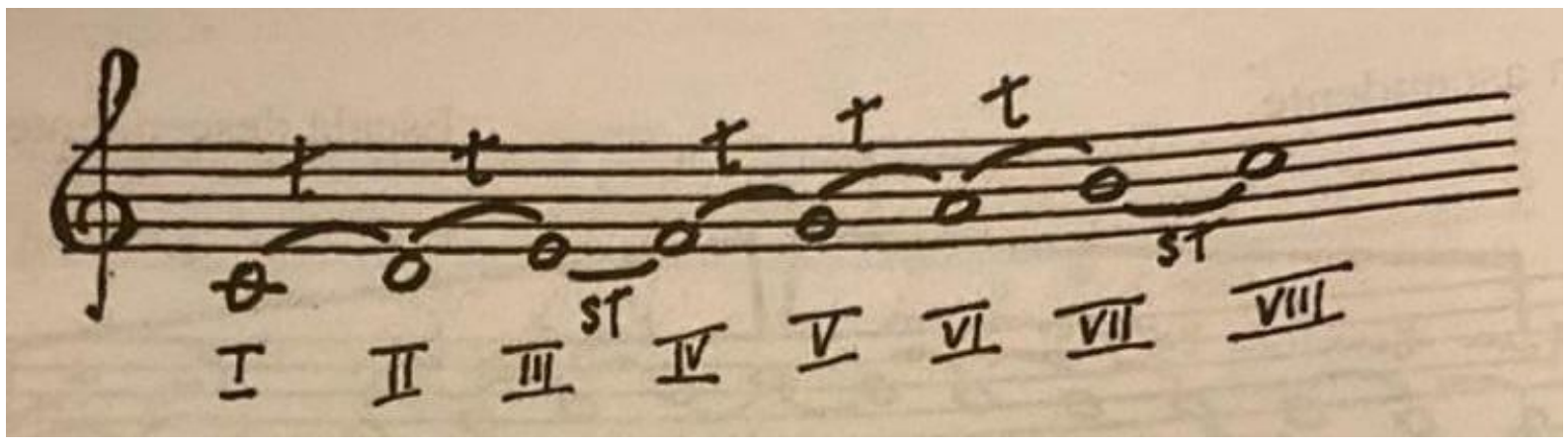

Fonte: Priolli, 2013, p. 30

Os graus da escala são assim denominados:

I grau - tônica

II grau - supertônica

III grau - mediante

IV grau - subdominante

V grau - dominante 
VI grau - superdominante

VII grau - sensível

VIII grau - tônica.

A escala diatônica é formada por 5 tons e 2 semitons. Os semitons são encontrados:

Do III grau para o IV.

Do VII para o VIII.

Os tons são encontrados:

Do I grau para o II.

Do II grau para o II

Do IV grau para o V

Do V grau para o VI

Do VI grau para o VII.

O I grau (tônica) é o mais importante da escala. Todos os demais graus têm com ele afinidade absoluta. E o I grau (tônica) que dá seu nome à escala e que a termina de um modo completo, sem nada deixar a desejar. 
Figura 4 - Escala ascendente e Escala descendente com identificação da Tônica



Fonte: Priolli, 2013, p. 30

Temos aí a nota Dó em função de tônica. Esta escala é, portanto, chamada escala de Dó, ou ainda escala no tom de Dó. Depois da tônica, as notas de maior importância são a dominante (V grau) e subdominante (IV grau). Os graus da escala também se classificam como conjuntos ou disjuntos. São conjuntos quando sucessivos, de acordo com sua relação de altura.

Figura 5 - Grau Conjunto

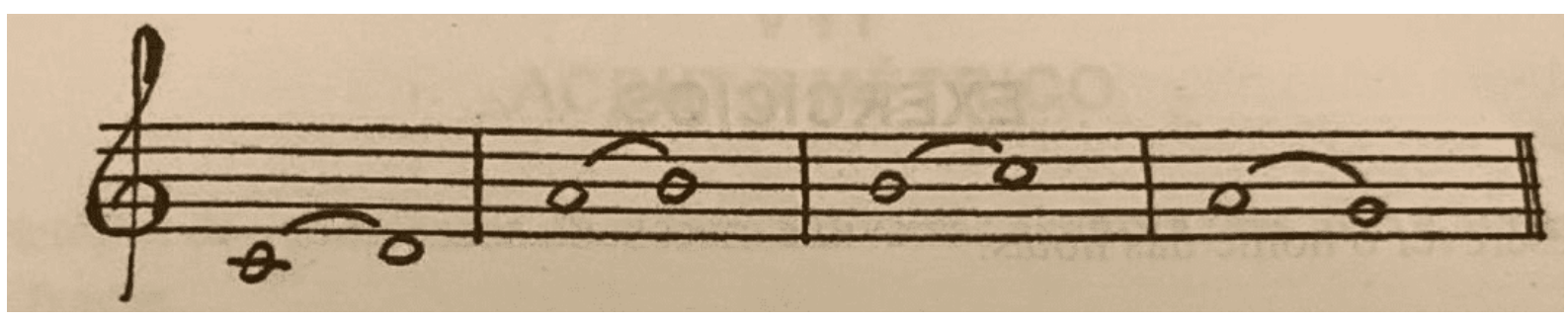

Fonte: Priolli, 2013, p. 31

São disjuntos quando entre ambos vem intercalado um ou mais graus. 
Figura 6 - Grau Disjunto

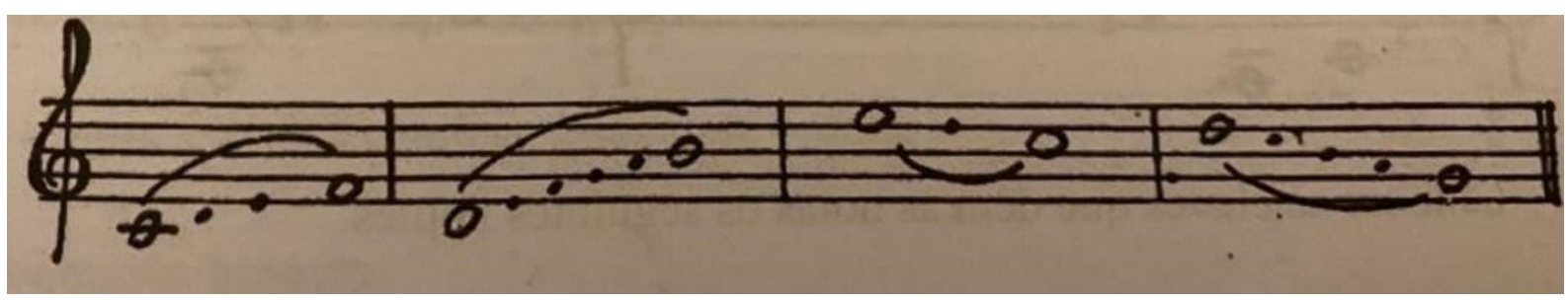

Fonte: Priolli, 2013, p. 31

\section{IMPLEMENTAÇÃO DO ARTEFACTO}

O artefacto foi desenvolvido em três fases: Inicialmente foi criada a parte física para se ligar à parte lógica através do Arduíno. Posteriormente foi testada a representação visual em copos. A última fase foi o teste em globos.

O circuito será alimentado através de alimentação simétrica, necessária para o funcionamento do amplificador operacional, fornecida por duas baterias de $9 \mathrm{~V}$ e uma fonte de $12 \mathrm{~V}$, para a alimentação da fita de LEDs, que deverá ser ligada a rede elétrica. O circuito de entrada possuirá três etapas: Excitação do microfone, Amplificação e Offset.

A excitação feita através de um resistor limitador de corrente e um acoplamento capacitivo é necessária para o funcionamento do microfone piezoelétrico. O microfone é geralmente feito de sal de Rochelle e apresentam diferença de tensão entre os terminais quando submetidos a forças mecânicas, no caso, o som.

A amplificação é feita através de um amplificador operacional na configuração não inversora. Vai ser configurado para apresentar ganho variável através da rotação do potenciômetro. A amplificação é necessária devido ao baixo nível de sinal proveniente do microfone. Para o tratamento digital é interessante que o sinal de entrada apresente uma tensão de pico a pico próxima a $5 \mathrm{~V}$.

O offset é feito a partir de um divisor de tensão e um acoplamento capacitivo da etapa de amplificação. Como o Arduino não consegue processar sinais negativos, é necessário elevar a parte negativa do sinal alternado gerado pelo microfone para o 
intervalo entre $0 \mathrm{~V}$ e $5 \mathrm{~V}$. O divisor de tensão será feito a partir da saída de $5 \mathrm{~V}$ do Arduino e aplicará uma tensão de $2,5 \mathrm{~V}$ à saída da etapa de amplificação. $\mathrm{O}$ acoplamento capacitivo vai impedir que a tensão contínua interfira na amplificação.

A etapa de saída possui um driver de potência que utiliza os princípios do circuito Darlington para controlar o "terra" dos leds (alta potência) através de uma etapa de controle de baixa potência (Arduino).

Para esta prática, após realizar o download da IDE no site do Arduino, conectei a placa na e realizei a configuração conforme indicado no tutorial. Foi inserido no programa o código fornecido, logo após compilado e carregado. Com auxílio da breadboard foi montado o circuito como indicado no esquema. Após compilar e carregar o novo código foi verificado que a luz do LED do circuito piscada da mesma forma que o LED do Arduino. Foi montado o circuito conforme o esquema, compilado o código à placa e como o potenciômetro tem uma informação variada ao girar a alavanca os LEDs ascendiam gradualmente. Para essa prática foi soldado dois jumpers no sensor piezoeléctrico depois foram montados o circuito conforme o esquema compilado o código é carregado para o Arduino. Ao pressionar o sensor o mesmo emitia um som.

\section{PROCESSAMENTO}

A frequência do sinal de entrada será reconhecida através da identificação de pontos de referência, como o valor de pico do sinal, na onda captada. A leitura do sinal de entrada ocorrerá em um intervalo contínuo e de alta frequência configurados por uma interrupção. As leituras serão processadas em tempo real para identificar os pontos de referência e através da diferença de tempo entre os pontos será calculada a frequência da onda.

Quando a frequência estiver no intervalo referente às notas da escala maior de Dó as respectivas cores serão reproduzidas na fita de LED.

O ensino da música é um conceito que pode ser considerado perene na sociedade, tão antiga quanto a própria existência da música e também causando conflitos 
cronológicos se forem estabelecer uma data de início dessa didática, levando em consideração que o ensino adquirido por oralidade dos antepassados também se encaixa nesse quesito didático.

Estamos na era digital; porque não unir o clarinete, um instrumento musical inventado no século XVII, no ano de 1690, com a tecnologia digital do século XXI? Foi pensando em responder essa pergunta que me propus a realizar o presente trabalho.

Considerando que as artes visuais, apropriando-se de meios tecnológicos, pode ser um elemento complementar à música, permitindo maior envolvimento emocional no público durante apresentações musicais, entende-se a importância de desenvolver trabalhos e estudos na área de modo a propagar os conceitos e incentivar produções criativas para solucionar problemas similares.

O contexto tecnológico se fez essencial para a evolução da temática, permitindo a reflexão sobre uma união entre artes visuais e música. Nesse contexto, surgiu a necessidade de um monitoramento ainda maior das relações com o público.

Aos poucos a popularização do computador e o surgimento da Internet, trouxe rapidamente grande volume de informações, aumentou a interatividade de pessoas de lugares diferentes e tornou os cidadãos muito mais conscientes e exigentes, assim como deu lugar para o surgimento de diversas formas de arte digital. Trouxe também maior amplitude das relações artísticas eletrônicas e novas necessidades até mesmo no mundo da música, que já não pode ser desarticulado dessa realidade.

É importante desenvolver trabalhos e estudos referentes à relação entre as Artes Visuais e a Música; a utilização de Artefatos Digitais na Educação Musical; e a consolidação das relações artísticas tecnológicas com a Música, na própria experiências.

\section{RESULTADOS E DISCUSSÕES}

Ao tentarmos associar as cores às notas musicais como estratégia de ensino precisamos observar e avaliar constantemente o desempenho e a aprendizagem dos 
alunos. A interação através do lúdico favorece a criação de um ambiente e método que incentivam a aprendizagem. Portanto, baseado em Piaget (apud MONTOYA, 2001) a criança estrutura a sua capacidade e seus conhecimentos a partir do seu meio ambiente e de si mesmo, através da estruturação de suas experiências e impressões e organização de seus instrumentos de expressão.

Logo, um estudante ao ter contato com um novo conteúdo, aprende e assimila com a ajuda das suas experimentações anteriores, e na expectativa de uma compreensão mais aprofundada, este estudante agrega este novo conhecimento aos que já possuía anteriormente. Assim, é importante que o docente busque inserir no contexto da educação ferramentas que também se encontram no cotidiano do estudante de música, estimulando o aprendizado do novo conhecimento.

Diremos então, a partir de Hippert (2018) que ao nos entendermos como seres culturais, participamos na construção dos significados dos elementos que compõem o mundo, e dialogam com a nossa experimentação sobre o mesmo, diariamente, e estes mesmo significados são construídos e usados coletivamente. Por exemplo, o uso da cor branca para simbolizar a paz, diremos o mesmo da marcha nupcial, ao ouvirmos jamais entenderemos que outro movimento acontece senão a noiva caminhando para o altar no dia do seu casamento.

Como constantemente falamos sobre percepção, não abandonaremos a proposição de que ela interfere na maneira como interpretamos o que nos rodeia, assim podemos dizer que os elementos com os quais convivemos nos afetam de tal modo que criamos relação a partir do que já experimentamos. Se sabemos de algo sobre algum objeto olharemos para ele a partir da relação entre nós e o objeto (BERGER, 1999 apud HIPPERT, 2018) pois o que vemos se evidencia muito antes de darmos um significado. Ou seja, caso não saibamos o que algo representa, associaremos a outro elemento para que possamos criar identificações, e posteriormente chegarmos à compreensão final. Quando não sabemos o significado/função/nome de uma coisa, procuraremos descrevê-la para que através desta "aproximação" encontremos a sua verdadeira identidade. 


\section{CONSIDERAÇÕES FINAIS}

Considerando que as artes visuais, apropriando-se de meios tecnológicos, pode ser um elemento complementar à música, permitindo maior envolvimento emocional no público durante apresentações musicais, entende-se a importância de desenvolver trabalhos e estudos na área de modo a propagar os conceitos e incentivar produções criativas para solucionar problemas similares.

Estamos na era digital; porque não unir o clarinete, um instrumento musical inventado no século XVII, no ano de 1690, com a tecnologia digital do século XXI? Foi pensando em responder essa pergunta que me propus a realizar o presente trabalho.

O contexto tecnológico se fez essencial para a evolução da temática, permitindo a reflexão sobre uma união entre artes visuais e música. Nesse contexto surgiu a necessidade de um monitoramento ainda maior das relações com o público.

É importante desenvolver trabalhos e estudos referentes à relação entre as Artes Visuais e a Música; a utilização de Artefatos Digitais na Educação Musical; e a consolidação das relações artísticas tecnológicas com a Música, na própria experiências.

\section{REFERÊNCIAS}

BEZERRA, V. A contribuição do movimento da dança quanto ao desenvolvimento das crianças de educação infantil: um estudo introdutório. Salvador: UNEB, 2009.

FERREIRA, et al. Educação Musical do passado ao Presente: Tecendo Caminhos Para Uma Educação De Melhor Qualidade. Unicruz, 2015.

HIPPERT, R. P. M. Ouver: A relação entre som e cor na percepção. Curitiba: UTFPR, 2018. 
LOUREIRO, A. M. O Ensino Da Música Na Escola Fundamental: Um Estudo Exploratório. Belo Horizonte: PUC, 2001.

MONTOYA, A. A Questão da Continuidade e Descontinuidade no ... In. Construtivismo e desafios da Educação, XVIII encontro do PROEPRE, UNICAMP, 2001.

PRIOLLI, M. L. M. Princípios Básicos de Música para a Juventude. 54. ed. rev. e atual. Rio de Janeiro: Casa Oliveira de Músicas LDTA., 2013. 142 p. v. 1.

MED, B. Teoria da Música - 4. ed., Brasília, DF: Musimed, 1996.

PORTUGAL, T. P.; CORRÊA, A. F. O conceito de ethos na música da Antiguidade Clássica grega. Rev. ORFEU, v. 2 n.1, jul de 2017, p. 204-225.

SANTOS, R. Música, cultura e educação: os múltiplos espaços da educação musical. 2. Porto Alegre: Sulina, 2012.

Enviado: Setembro, 2020.

Aprovado: Setembro, 2020. 